\title{
Saturation of barrier materials under thermal gradient
}

\author{
María Victoria Villar, Pedro Luis Martín, Francisco Javier Romero, Rubén Javier \\ Iglesias, Vanesa Gutiérrez-Rodrigo
}

CIEMAT, Avd. Complutense 40, 28040 Madrid, Spain

The backfilling and sealing of deposition galleries or holes and access galleries and shafts is an important part of nuclear waste underground repository design. Any opening created during the construction of the repository is a potential preferential pathway for water, gas and radionuclides migration, and has to be effectively sealed. Bentonite or bentonite-based mixtures have been proposed as backfill and sealing materials for their low permeability, high swelling capacity and high retention capacity.

This work reports the results of two laboratory tests in which two different sealing materials were subjected to conditions similar to those in a repository: a high thermal gradient and hydration with host rock water (Figure 1). The materials are contained in cylindrical cells with a plane heater at the bottom and water supply through the top surface. The temperature and relative humidity (RH) of the materials are measured online during the tests by capacitive sensors placed at different positions. The water intake and the heater power are also measured online. In addition, cell B is instrumented with a ring load cell located on the top of the cell to determine the axial pressure generated during the test.

In one of them the material used is MX80 bentonite pellets (B) and in the other is a 65/35 sand/bentonite mixture (S/B). The superficial thermal conductivity of these granular materials in their as-received state are 0.33 and $0.12 \mathrm{~W} / \mathrm{m} \cdot \mathrm{K}$ for the mixture and the pellets, respectively. The $\mathrm{S} / \mathrm{B}$ mixture has a predominant macroporosity with a pore mode about $204 \mu \mathrm{m}$, whereas in the B pellets mesopores of pore mode about $0.014 \mu \mathrm{m}$ predominate (Villar 2013). For a dry density of $1.53 \mathrm{~g} / \mathrm{cm}^{3}$ a swelling pressure of about $4 \mathrm{MPa}$ is expected for MX-80 bentonite and of $0.15 \mathrm{MPa}$ for the sand/bentonite mixture at a nominal dry density of $1.45 \mathrm{~g} / \mathrm{cm}^{3}$. These values were obtained with deionised water, but they are expected to be lower if the saturation water is saline.

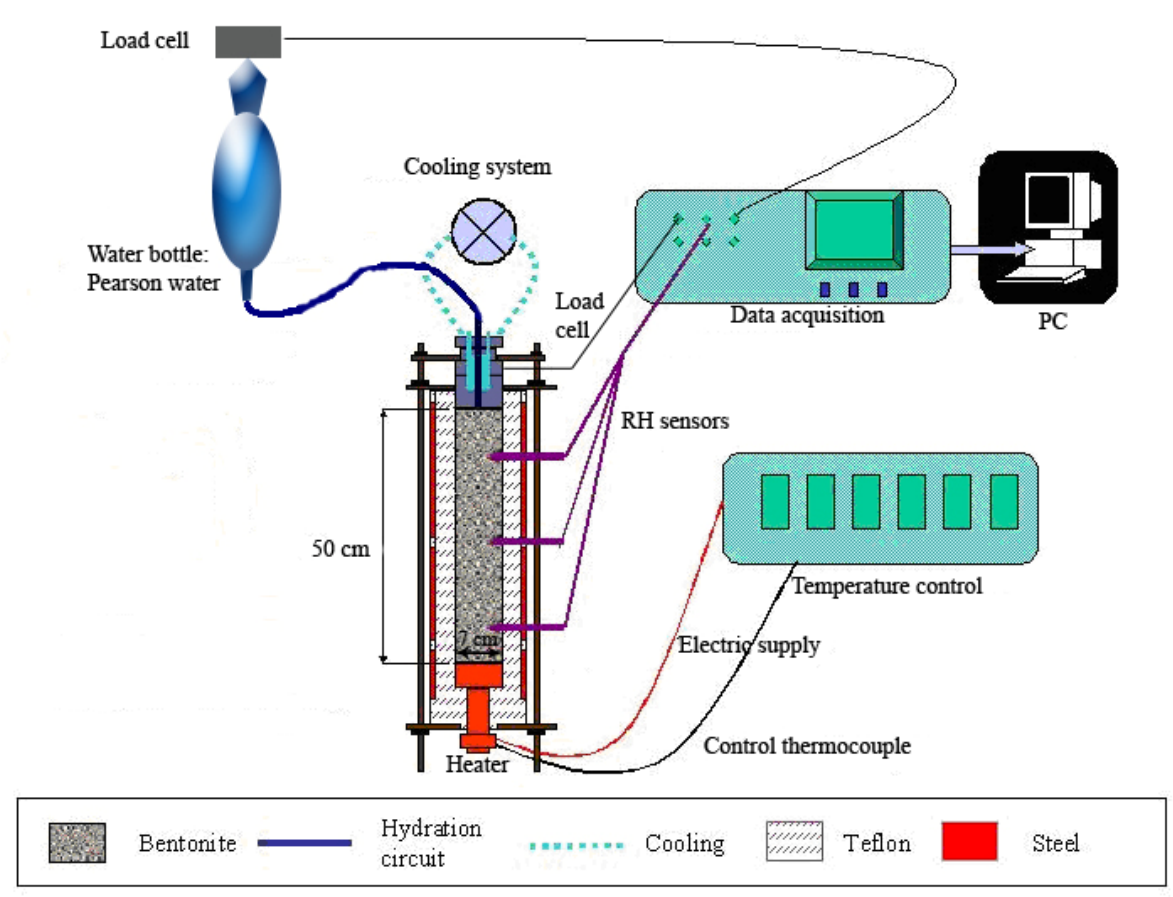

Figure 1: Experimental setup for the infiltration tests 
The initial water content and the average dry density of the materials inside the cells were $5.9 \%$ and $1.46 \mathrm{~kg} / \mathrm{m}^{3}$ for the B pellets and around $4 \%$ and $1.5 \mathrm{~g} / \mathrm{cm}^{3}$ for the $\mathrm{S} / \mathrm{B}$ mixture.The tests were performed in two stages. In the first one, only a thermal gradient was prescribed with

no hydration taking place. This stage tries to simulate the early stage of a barrier in a low-permeability argillaceous rock where hydration from the host medium will be minimal.The temperature of the heaters placed at the bottom of the columns was increased to $100^{\circ} \mathrm{C}$ and then to $140^{\circ} \mathrm{C}$. The stabilisation of the temperature was very quick; the low thermal conductivity of the dry materials caused a high thermal gradient near the heater, and low temperatures in the rest of the columns. The movement of water in the vapour phase as a result of the thermal gradient was evinced by the sharp increase of relative humidity recorded by the sensors closest to the heater -followed by a continuous decrease- and the slower increase recorded in the middle and upper parts of the columns. The different permeability of both materials was made clear in the different pace and extent of this water redistribution process in the vapour phase, which was faster for the S/B mixture. Also the relative humidity gradient at the end of the heating phase was sharper in cell $\mathrm{S} / \mathrm{B}$, due to the lower permeability and higher water retention capacity of the bentonite pellets (Figure 2).

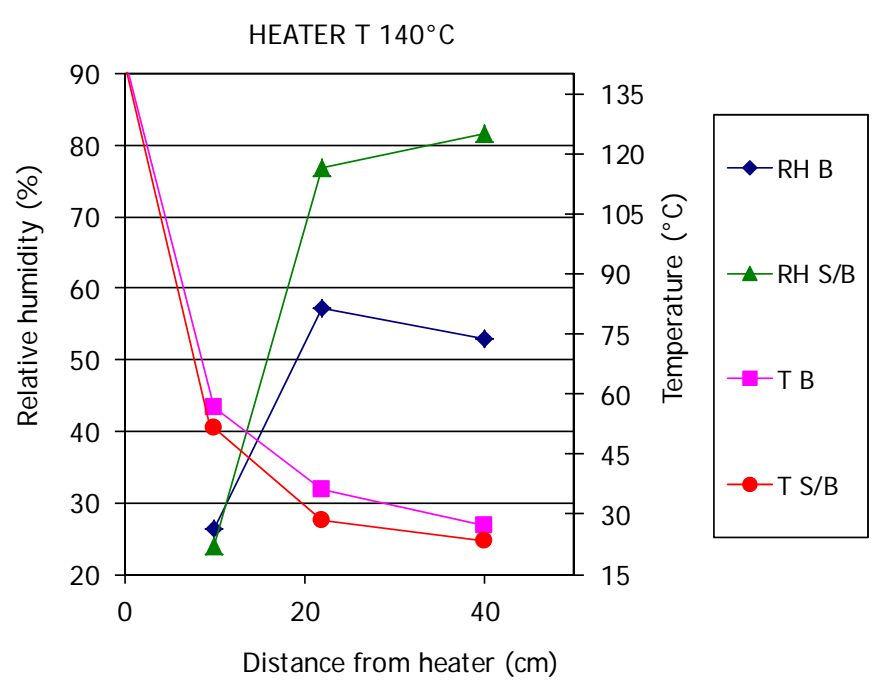

Figure 2: Temperature and relative humidity inside the materials at the end of the heating phase

Hydration with saline water through the upper surface of the columns started after RH stabilisation inside the materials. A small pressure, given by a $40-\mathrm{cm}$ height water column, was applied to the saturation water. The temperatures kept the same after hydration started for more than 500 days in the case of cell B but only for some days in cell S/B. In the latter case, as the water front approached the sensors, the temperatures increased, and thus the increase in temperature and relative humidity was simultaneous and sudden (Figure 3, left). The reason is probably the increase in thermal conductivity of the S/B material after being completely saturated. The increase in temperature due to the increase of water content was of $16^{\circ} \mathrm{C}$ at $10 \mathrm{~cm}$ from the heater. The lower permeability of the pellets was again highlighted when hydration started, because the sensors started to record RH increases much later than in cell S/B. In fact, after 1000 days of hydration the relative humidity gradient along the column was steep, with the sensor located at $10 \mathrm{~cm}$ from the heater recording relative humidity below the initial value (Figure 3, right). The average bentonite water content and degree of saturation, according to the water intake measurements, were only $18.2 \%$ and $63 \%$, respectively, and an axial pressure of $1.5 \mathrm{MPa}$ had been developed.

On the contrary, the three sensors in column S/B were flooded after 300 hours, and the measurement of the water intake indicated full saturation after 500 days of hydration. The cell was dismantled after 2.8 years of operation. The column had a cohesive consistence and it was possible to cut it into sections and determine in them the water content and dry density (Figure 4), which were homogeneous along the column and corresponded to degrees of saturation higher than $90 \%$. Only in the two centimetres closest to the heater the material was dry and loose. It has been checked that the salinity in this part of the column was extremely high. 

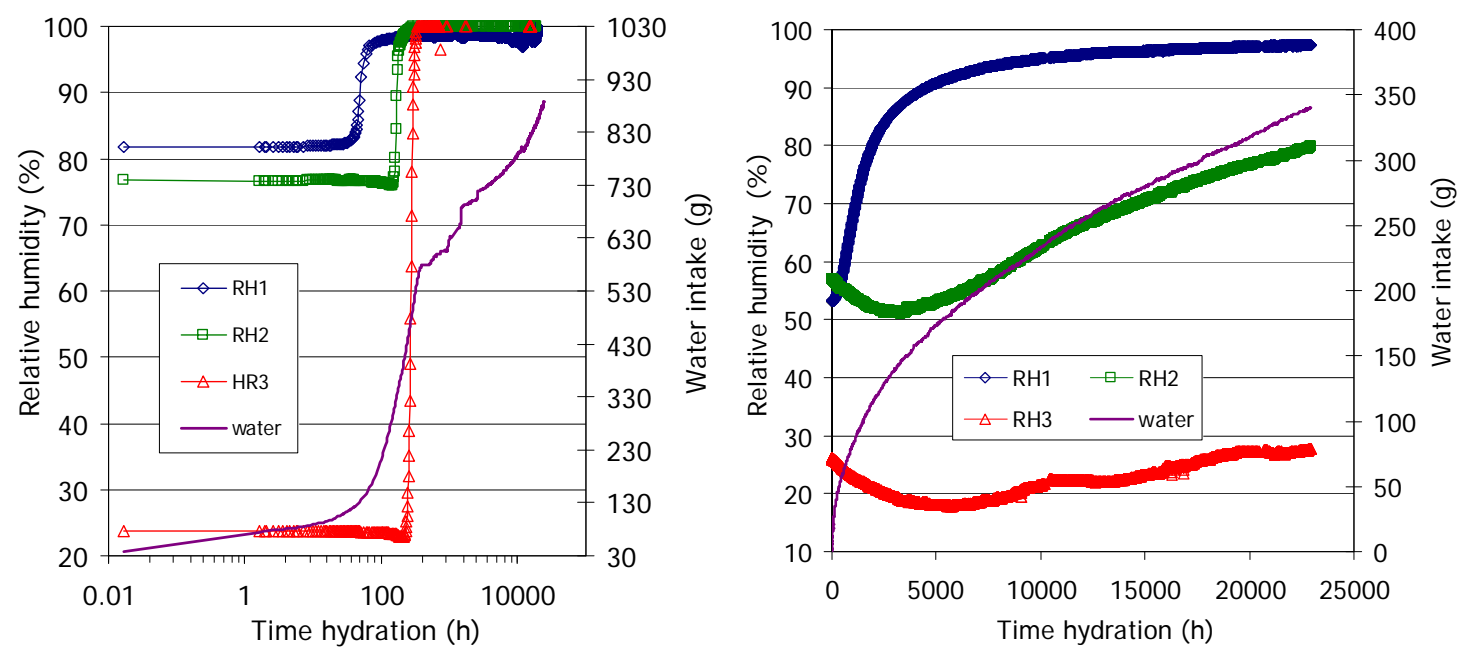

Figure 3: Evolution of relative humidity inside the bentonite and water intake in cell S/B (left) and B (right) during the hydration phase (sensor 1 placed at $40 \mathrm{~cm}$ from the bottom, sensor 2 at $22 \mathrm{~cm}$ and sensor 3 at $10 \mathrm{~cm}$ ).

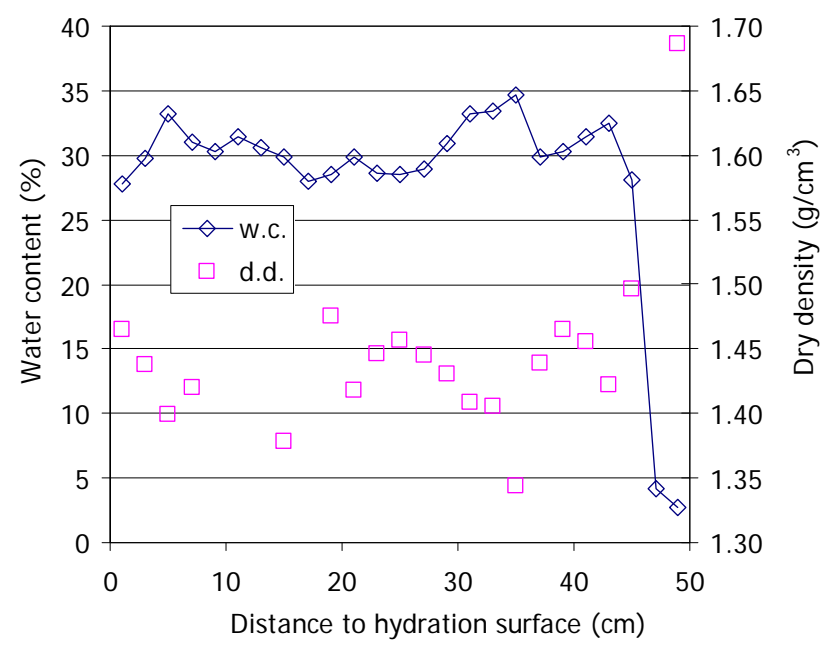

Figure 4: Final water content and dry density along the column at the end of test S/B

The THM behaviour of the materials tested depended mainly on their permeability and swelling capacity. The B pellets saturated slowly and developed simultaneously swelling pressure: as it has been repeatedly shown it is an appropriate material for sealing of repositories. On the other hand, the S/B mixture saturated quickly but swelled enough to close the largest pores: it would probably be more suitable as backfill material, for which high gas permeability is required.

\section{Acknowledgements}

The research leading to these results received funding from the European Atomic Energy Community's Seventh Framework Programme (FP7/2007-2011) under Grant Agreement no249681, the PEBS project and from ENRESA. It is currently being financed by the Mont Terri Consortium, project HE-E. The laboratory work was performed by Ramón Campos and Juan Aroz.

\section{References}

Villar, M.V.; Martín, P.L.; Gómez-Espina, R.; Romero, F.J. \& Barcala, J.M. 2012. Long-term THM tests reports: THM cells for the HE-E test: setup and first results. PEBS Deliverable 2.2-7.1. CIEMAT Technical Report CIEMAT/DMA/2G210/03/2012. Madrid, 27 pp. 